\title{
Dino BuZZATI
}

Seixanta contes,

trad. de Joaquim Gestí, pròleg de Julià de Jòdar, Barcelona: Edicions de 1984, 2004.

A hores d'ara, s'han consolidat tres maneres diferents de llegir l'obra de Dino Buzzati. Segons la primera, a la seva obra mestra, la novel.la El desert dels Tàrtars, de 1940 , l'autor ja havia dit tot el que havia de dir. Es tractaria, al cap i a la fi, d'un Kafka dimidiatus, amb una col.locació imprecisa dins la galàxia del Novecento - on la línia més breu entre dos punts, com solia dir Flaiano, es representada per l'arabesc- - Així, doncs, de Calvino a Cassola tot es pot juxtaposar, i ni a Buzzati se li nega un petit nínxol per la felicitat dels apassionats, encara que se li faci pesar la duplicitat de la seva ànima d'escriptor periodista, un aparellament que, a la tradició literària italiana — fundada sobre sòlides arrels puristes-, sempre ha estat menystingut.

La segona lectura és la de Buzzati fora d'Itàlia. En van ser capdavanters els francesos, que han sabut fer interactuar de manera magistral l'autor menys afrancesat de tota la literatura italiana amb la seva pléiade. Als Països Catalans, en un intent d'abordar l'autor des de l'òptica comparatista, Buzzati ha estat posat al costat de Pere Calders amb una insistència que, tanmateix, no ha deixat fins ara cap rastre significatiu. Des d'una altra perspectiva, també caldria assenyalar en aquesta secció el pròleg al volum dels Seixanta contes, on Julià de Jòdar ens dóna unes idees engrescadores amb una visió personalitzada de l'obra de Buzzati. Amb tot, no es tracta d'una aproximació crítica, sinó d'un apadrinament literari, de la nota lúcida d'un escriptor que, com a tal, llegeix un altre escriptor.

Hi ha una tercera manera de llegir Buzzati, i la va exemplificar Silvana Cirillo en proposar la categoria dels autors «al llindar» —això és, aquells que es troben un pas ençà de la consagració canònica-
Buzzati es trobava en companyia d'Alvaro, Delfini, Landolfi, Zavattini i Malerba. Si, de la llista, en traiem el darrer nom, car és l'únic autor viu -i en plena producció-, i hi afegim Savinio i Bontempelli, es configura una mena de camí surrealista à l'italienne, una espècie de regnat de la fantasia que, després de la Segona Guerra Mundial, ha estat ofuscat pel pas de l'astre encegador del neorealisme. La definició, més que imperfecta, és metaforica, però és millor fer servir una incorrecció declarada que recórrer a una expressió tan desgastada com «realisme màgic», que arrossegaria un seguit $\mathrm{d}$ 'incomprensions infinites.

El que cal puntualitzar és que Buzzati no ha estat profeta en la seva pàtria. Qui s'abelleixi a fullejar qualsevol història de la literatura italiana del segle XX, subscriurà facilment aquesta constatació. Genèricament, se sol dividir un Buzzati bo d'un Buzzati que cedeix a la temptació del bestseller o, més ben dit, un Buzzati inicial d'un Buzzati madur, amb una fissura que té lloc al començament dels anys seixanta. De fet, al darrere hi ha una explicació històrica. De 1963 és Un amore, que fou la seva novel.la més discutida, i la mateixa data assenyala, per antonomàsia, la maduració completa de la neoavantguarda italiana (i, de pas, és el mateix any de la publicació del Lessico famigliare, de Natalia Ginzburg). Així doncs, Buzzati, que primer havia estat rebutjat per les seves derivacions cap al món fantàstic durant el domini del neorealisme, en un segon moment serà rebutjat com a conservador —en el camp literari i ideològic- per part dels nous models emergents.

Però Buzzati anava molt més enllà $i$ aquests Seixanta contes, traduïts amb una gran habilitat per Joaquim Gestí, en són la demostració. Era pintor i crític d'art, 
com s'aprecia als contes «Batalla nocturna a la Biennal de Venècia» $i$ "El crític d'art». Era capaç d'endinsar-se en la ciència i en la ciència-ficció, com ho demostra a «La d'hidrogen", "El disc aterrà» $\mathrm{o}$ "Cita amb Einstein"; i no es feia enrere davant el debat etològic, del qual es generaven contes com ara "Vell facoquer", "Les rates» o fins i tot «La mort del drac». Malgrat que hagi estat titllat d'escriptor catòlic, Buzzati era en realitat un agnòstic que sabia narrar les experiències religioses, i alguns dels seus contes més coneguts, «El gos que va veure Déu», "Les temptacions de Sant Antoni» o "La fi del món», necessiten encara una interpretació escaient per establir on acaba el pretès sentiment de solidaritat ecumènica i on comença la més que probable ironia. També hi ha un Buzzati músic i crític musical, del qual podem gaudir a través de les narracions "El músic envejós» o "Por a l'Scala», i seria bo assaborir el conte "Una gota» tot escoltant Les jeux d'eaux à la Villa d'Este, de Liszt. La pièce dura set minuts i mig — amb la qual cosa caldrà llegir la narració a poc a poci la correspondència no és gens didascàlica. Però, si el lector n'accepta el joc, tindrà la sensació de trobar-se dins un cinema dels anys vint amb un pianista a la sala que acompanya les imatges escandint les seves notes. I haurà respectat aquella voluntat de tècnica mixta que havia empès l'autor a escriure una obra com el seu Poema a fumetti. Tampoc la traducció no serà un obstacle per a aquesta lectura musical, només cal mirar el final del conte per adonar-se'n: «Ma no, vi dico, non è uno scherzo, non ci sono doppi sensi, trattasi, ahimé proprio di una goccia d'acqua, a quanto è dato presumere, che di notte viene su per le scale. Tic, tic, misteriosamente, di gradino in gradino. E perciò si ha paura». L'angoixa que al text italià prepara el lector cap a la frase conclusiva, amb aquells accents martellejants sobre les is, és reproduïda a la versió catalana amb un accent que, al final, cau de manera sistemàtica sobre la $o$ i que desemboca en la darrera paraula: "Però ja us he dit que no, no és cap broma, no hi ha dobles sentits, es tracta, valgui'm Déu, només d'una gota d'aigua, pel que es pot deduir, que de nit puja per les escales: tic, tic, misteriosament, de graó en graó. I per això ens fa por».

Francesco Ardolino 